\title{
Development of a multiparametric (bio)sensing platform for continuous monitoring of stress metabolites
}

Ayman Chmayssem, ${ }^{*}$ Nicolas Verplanck, ${ }^{b}$ Constantin Edi Tanase, ${ }^{c}$ Guillaume Costa, ${ }^{a}$ Karen MonsalveGrijalba, ${ }^{a}$ Simon Amigues, ${ }^{a}$ Mélanie Alias, ${ }^{a}$ Maxime Gougis, ${ }^{a}$ Véronique Mourier, ${ }^{a}$ Séverine Vignoud, ${ }^{a}$ Amir M. Ghaemmaghami ${ }^{c}$ and Pascal Mailley ${ }^{*} a$

(a) Univ. Grenoble Alpes, CEA, LETI, DTBS, L2CB, F-38000 Grenoble, France

(b) Univ. Grenoble Alpes, CEA, LETI, DTBS, LSMB, F-38000 Grenoble, France

(c) Immunology \& Immuno-Bioengineering Group, School of Life Sciences, Faculty of Medicine \& Health Sciences, University of Nottingham, United Kingdom

*Corresponding authors: pascal.mailley@cea.fr ayman.chmayssem@cea.fr

\begin{abstract}
There is a growing need for real-time monitoring of metabolic products that could reflect cell damages over extended periods. In this paper, we report the design and development of an original multiparametric (bio)sensing platform that is tailored for the real-time monitoring of cell metabolites derived from cell cultures. Most attractive features of our developed electrochemical (bio)sensing platform are its easy manufacturing process, that enables seamless scale-up, modular and versatile approach, and low cost. In addition, the developed platform allows a multiparametric analysis instead of single-analyte analysis. Here we provide an overview of the sensors-based analysis of four main factors that can indicate a possible cell deterioration problem during cell-culture: $\mathrm{pH}$, hydrogen peroxide, nitric oxide/nitrite and lactate. Herein, we are proposing a sensors platform based on thick-film coupled to microfluidic technology that can be integrated into any microfluidic system using Luer-lock connectors. This platform allows obtaining an accurate analysis of the secreting stress metabolites during cell/tissues culture.
\end{abstract}

\section{KEYWORDS}

Electrochemical sensors, Multiparametric platform, Stress metabolites monitoring, Microfluidic technology.

\section{INTRODUCTION}

The sharp increase in development and testing of new biomaterials in recent years means that there is a real need for higher throughput screening systems in the biomedical field to accelerate the development of new and improved implant biomaterials with lower costs [1-4]. Conventional in vitro cell culture experimental set-ups are used in early stages of development to characterize cell culture/biomaterials interactions. However, these simplistic systems are now recognized to fall short in mimicking the natural in vivo microenvironment thus delivering poorly predictive outputs.

Organs-on-chips are microengineered cell culture devices that recapitulate physiological functions and closely mimic the cellular microenvironment found in vivo $[5,6]$. They are expected to provide more predictive pre-clinical tools than standard in vitro models [7-9]. To provide an accurate analysis of the stress imposed by the tested biomaterials, cells/tissues need to be surrounded by a range of (bio)sensors for real-time monitoring of inflammatory biomarkers [10,11]. Indeed, acute stress of biological tissues is accompanied by the secretion of direct (chemokines and cytokines) and non-direct inflammatory biomarkers [12]. While measuring cytokines and chemokines is informative, changes in these factors could take significant amount of time. Therefore, monitoring of non-direct parameters associated to cell metabolism such ions $\left(\mathrm{H}^{+}, \mathrm{Na}^{+}\right.$, $\mathrm{K}^{+}, \mathrm{Ca}^{2+}, \mathrm{Mg}^{2+}, \mathrm{NO}_{2}^{-}$and $\left.\mathrm{NO}_{3}^{-}\right)$, chemicals (ROS, glucose and lactate) and dissolved gases $\left(\mathrm{O}_{2}, \mathrm{CO}_{2}\right.$ and $\mathrm{NO}$ ) is of particular interest. Such monitoring would provide some valuable insights; first, on cell behavior and microenvironment during cell growth and/or, secondly, on cell stress when cell cultures are submitted to biomaterial testing [13]. 
Indeed, cell behavior and metabolic activity are related to the nature of the monitored cell cultures [14]. Thereby, the screening parameters have to be generic to a variety of organ tissues culture based on their relevance and their implication in the inflammatory process. Briefly, inorganic ion concentrations as well as $\mathrm{pH}$ have to be carefully managed to provide an adequate microenvironment for cell culture $[15,16]$. However, except proton and nitrogen-based anions, ions provide poor information on tissue inflammation. It is worthwhile to mention that nitrates and nitrites are more specific to the inflammation process. Practically, both anions are issued from nitric oxide oxidative degradation in presence of dissolved oxygen. Indeed, NO is poorly stable (half time life of few tens of seconds) and reacts rapidly with dissolved oxygen to produce consecutively nitrite and nitrate anions $[17,18]$. However, monitoring of nitrogen-based anions, which accumulates within the culture media, is not a reliable parameter in regard to NO due to its slow temporal evolution that will provide poor insights on acute phenomena [19]. On the other hand, reactive oxygen species (ROS) including oxygen radicals (superoxide radical and hydroxyl radical) and non-radical derivatives (hydrogen peroxide, hypochlorite...) are known to produce effects on cellular physiology [20]. At low to moderate concentrations, these molecules act as signal to promote cell proliferation and survival. In healthy tissues, ROS generation is balanced by antioxidant species production. However, environmental stressors can contribute to an excessive production of ROS inducing cell death [21]. From the different aforementioned species, hydrogen peroxide $\left(\mathrm{H}_{2} \mathrm{O}_{2}\right)$ is a more stable diffusive species which is strongly related to inflammation and together with NO represents a target of choice for the characterization of inflammation process [22]. Besides, lactate is one of the main studied molecular metabolites for cell culture monitoring as a product of cell respiration dysfunction. Practically, lactate production occurs under hypoxic conditions or as a consequence of high flux of glycolysis in proliferating cells [23]. Therefore, as a representative and stable biomarker of inflammation, monitoring lactate concentration, which accumulates within the culture media, is of high interest.

Nevertheless, numerous papers have described the design of individual sensors for the detection of one or two of these parameters [23,24]. More recently, some papers have reported the development of a multiparametric sensing platform for the detection in vivo of metabolic species such as glucose, lactate, glutamate and oxygen [25-27]. However, the development of sensors for the detection of the selected metabolites (oxygen species $\left(\mathrm{NO}, \mathrm{H}_{2} \mathrm{O}_{2}\right.$ ) in addition to $\mathrm{pH}$ and lactate) in a multiparametric configuration combining the use of microfluidic technology have never been developed and reported. So, a multiparametric (bio)sensing platform is needed for the real time monitoring of the cellular metabolites.

In this study, we report the development of a multiparametric (bio)sensing platform for real-time monitoring of a selected cellular metabolites (oxygen species $\left(\mathrm{NO}, \mathrm{H}_{2} \mathrm{O}_{2}\right.$ ) in addition to $\mathrm{pH}$ and lactate). This platform is integrated into a dedicated microfluidic system allowing a direct contact with the cell-culture microenvironment under flow. The development of all (bio)sensors was achieved using the same technological basis involving screen-printing of the electrodes and drop-casting of the sensitive (bio)membranes. Herein, we demonstrate that this modular set-up provides a powerful toolkit for the detection of metabolites issued from the inflammatory process for in vitro testing. This contribution focused on the development of the latter analytical tool.

\section{MATERIALS AND METHODS}

\subsection{Chemicals, Buffers and Solutions}

Sodium hydroxide solution ( $\mathrm{NaOH}$ - Titripur® Reag, $1 \mathrm{M})$ and hydrochloric acid $(\mathrm{HCl}$ - ACS reagent, 37\%) were purchased from Merck and were used for the adjustment of media $\mathrm{pH}$. Stock solution of hydrogen peroxide $\left(\mathrm{H}_{2} \mathrm{O}_{2} 30 \%\right.$, CAS: 7722-84-1) was also obtained from Merck and utilized for the preparation of standard solutions. Stock solution of phosphate-buffered saline (PBS 10x) was purchased from SigmaAldrich and utilized for the preparation of working solution (PBS $1 \times \mathrm{pH} 7,4)$. Sodium nitrite $\left(\mathrm{NaNO}_{2}\right.$ - purity $>99 \%$, CAS: 7632-00-0) and DL-Lactic acid sodium salt (2-Hydroxypropionic acid - ReagentPlus $\AA_{\text {, }}$, purity $\geq 99 \%$, CAS: $72-17-3$ ) were also obtained from Sigma-Aldrich and used for the preparation of standard solutions. Lactate oxidase (LOX - EC \# 1.13.12.4) was purchased from Sorachim and was employed in the 
preparation of lactate sensor. Iridium (IV) oxide ( $\mathrm{IrO}_{2} .2 \mathrm{H}_{2} \mathrm{O}$, CAS: $\left.30980-84-8\right)$ was obtained from SigmaAldrich and used in the mixer of carbon paste for the preparation of $\mathrm{pH}$ sensor. Deionized water was obtained in our laboratory by an appropriate production system (Millipore). Other chemicals used in this study were of analytical reagents grade.

\subsection{Apparatus}

Screen-printer EKRA E4 was utilized for the fabrication of electrochemical biosensing platform under clean room conditions. Lab oven (Memmert UM100) was used after the screen-printing steps for ink/paste drying. Metrohm pH Meter systems (model $827 \mathrm{pH}$ Lab meter) have been used for the adjustment of media $\mathrm{pH}$. Syringe pump (PHD 2000 Infusion) acquired from Harvard Apparatus was used to work under flow conditions (100 $\mu \mathrm{L} \cdot \mathrm{min}^{-1}$ ). Multichannel potentiostat (VPM-300) purchased from BioLogic Science Instruments was used for simultaneous measurements of electrochemical signal using NStat mode (CE to ground configuration). EC-lab ${ }^{\circledR}$ software (V11.34) was employed for the electrochemical data processing.

\subsection{Mechanical and Electrical design}

The electrochemical (bio)sensing platform has been designed as shown on Figure 1a. This platform integrates on the same support the reference electrode $(R E)$ in the center of the design ( $3 \mathrm{~mm}), 1$ big annular counter-electrode (CE) and up to 8 working electrodes of 1,6 $\mathrm{mm}$ diameter.

In terms of electrodes size and position, the platform has been designed according to the electrochemical standards of sensors development. So far, the counter electrode has a surface area more than three times than the sum of the area of the eight working electrodes. The positioning of different working electrodes are designed to avoid cross-interferences between the different sensing pads. Nevertheless, all the WE are similarly positioned equidistantly from RE and CE.

A printed circuit board (PCB) is used as support for the biosensing platform (Fig. S1). Tracks and electrodes are made of copper and platted with a gold layer (tens of $\mathrm{nm}$ ). A UV-curable dielectric film covers the conductive tracks, except the connecting pads. Gold is not directly used as electrode material and is further covered by different materials to provide each electrode the required properties. First, a carbon layer is printed at the surface of all the electrodes. This carbon layer is implemented to promote the adhesion of the active layers for the different electrodes except for the counter electrode for which it is used as counter electrode material. For the reference electrode, a silver/silver chloride layer is deposited at the top of the carbon layer. The development of all (bio)sensors is achieved using drop-casting or inkjet printing of the sensitive (bio)membranes on the carbon electrodes.

The aforementioned PCB support is then mounted in a polymer-based microfluidic chamber. Indeed, this microfluidic chamber was designed taking account the volumes, the viscosity and the flux of fluids (Figure 1a). Cyclic olefin copolymer ( $\mathrm{CoC})$ have been chosen as a machining material for the fabrication of microfluidic chamber for its physico-chemical and biological properties (e.g. biocompatibility, low adsorption capabilities, transparent, resistant to autoclave sterilization). The microfluidic chamber was assembled to the electrochemical platform using a double-sided pre-cutting tape (Fig. S2). Mini Luer-Lock connectors purchased from Microfluidic-ChipShop (Fluidic 263 - 10000080) were used to bring the fluid through the inlet position of the flow cell.

The depth of the microfluidic chamber is of $300 \mu \mathrm{m}$ leading to a volume of around $190 \mu \mathrm{L}$. This ensure a total fluid regeneration in the chamber each 2 minutes under a flow rate of $100 \mu \mathrm{L}$. $\mathrm{min}^{-1}$ with the required flow rate for our application. Nevertheless, the chamber volume can be adapted to host more or less volume of liquid depending on the application (Fig. 1b).

The electrical design of the integrated platform has been developed to be connected using Molex connector: 1.0 Pitch SMT FFC/FPC (REF: 49456-1017) that typically presents 250 mating cycles. This connector was connected to the potentiostat via an electrical connection board (Fig. S3 and S4).

\subsection{Biosensing layer formulation and platform functionalization}


For the multiparametric biosensing platform, four parameters are selected as follow: $\mathrm{pH}$, hydrogen peroxide, nitric oxide/nitrite (NO and its by-product) and lactate. For these parameters, the working electrodes are functionalized by screen-printing or drop casting of the different sensitive layers.

For $\mathrm{pH}$ sensing, we developed a specific formulation by blending previously used carbon-based ink and iridium oxide powder. This formulation is then screen-printed as sensitive layer for pH monitoring (Fig. 2a). For hydrogen peroxide sensing, a Prussian blue carbon-graphite based ink (purchased from Gwent material, C2070424P2) is screen-printed (Fig. 2b). For nitric oxide/nitrite sensing, a carbon-graphite paste containing Meldola's Blue mediator (purchased from Gwent material, C2030519P5) is utilized as sensitive layer (Fig. 2c). For lactate sensing, an enzymatic biosensor based on lactate oxidase was developed. This biosensor is composed of hydrogen peroxide sensitive layer (Prussian blue carbon-graphite based ink purchased from Gwent material, C2070424P2) on which is deposited an enzyme biolayer consisting on cross-linking the enzyme with Glutaraldehyde as described in the literature [28-31] (Fig. 2d).

First, in the view of reproducibility study of the sensitive layers, the $\mu$ fluidic platform was used for electrochemical sensing of one parameter by up to eight working electrodes. To achieve this goal, the same sensitive layer is deposited on all the working electrodes for the selected sensing parameter. Secondly, the platform was used for simultaneous sensing of the four different parameters. The working electrodes were functionalized by pairs with the different sensing membranes using the aforementioned protocols.

The different (bio)sensors were localized on the platform according to analyte flux to avoid crossinterferences between the different sensing pads (Fig. S5). The screen-printed and drop-casted inks/pastes have been dried according to the manufacturer instructions.

\subsection{Cell culture}

Immortalized cell line of human colorectal adenocarcinoma-Caco-2 (ATCC ${ }^{\circledR}$ HTB-37 ${ }^{\mathrm{TM}}$ ) were maintained in Dulbecco's modified Eagle's medium (DMEM) (Sigma-Aldrich, UK) supplemented with 10\% FBS, MEM non-essential amino acids (Gibco, Thermo Fisher Scientific, UK), 1 M HEPES (Gibco, UK), 100 mM sodium pyruvate (Gibco, UK), $200 \mathrm{mM}$ GlutaMAX (Gibco, UK), and penicillin-streptomycin (Sigma-Aldrich, UK), cultured at $37^{\circ} \mathrm{C}, 5 \% \mathrm{CO}_{2}$ and $90 \%$ relative humidity.

Caco-2 cells were cultured on PET Transwell ${ }^{\circledR}$ at $5 \times 10^{5} \mathrm{cells} / \mathrm{cm}^{2}$. The culture medium was replaced every 2-3 days. After 21 days of culture, the cells were exposed for $24 \mathrm{~h}$ to sodium dodecyl sulfate (SDS) solution $0.5 \mathrm{mM}$, a well-known substance impacting the integrity of Caco-2 cells, used as positive control for cytotoxicity evaluation [32,33]. After SDS exposure the media was collected and used for analysis on the multiparametric (bio)sensing platform. Samples without SDS exposure were used as control for this experiment.

\section{RESULTS AND DISCUSSION}

The main parameters selected for electrochemical detection by the (bio)sensors were: $\mathrm{pH}$, hydrogen peroxide, nitric oxide (ROS) and lactate. Different electroanalytical methodologies were involved in the design of the different (bio)sensors. $\mathrm{pH}$ measurements deal with potentiometric detection owing the use of a redox $\mathrm{pH}$ material $\left(\mathrm{IrO}_{2}\right)$ [34]. The nitric oxide and hydrogen peroxide were detected amperometrically owing to the use of a catalyst modified carbon materials [24,35]. Lactate monitoring was effected using an amperometric enzymatic biosensor that embed the enzyme lactate oxidase [36]. The (bio)sensors platform has been characterized in artificial fluid (PBS solution) by determining the limit of detection, the sensitivity, the selectivity, the response time and the dynamic range of each sensor.

\section{1. $\quad \mathrm{pH}$ sensing}

Many technological approaches are available for the development of $\mathrm{pH}$ sensor including glass electrodes [37], ion sensitive field effect transistors (ISFET), ion-selective electrodes (ISE), and redox-material based electrodes (such as polyaniline (PANI) and iridium oxide ( $\left.\mathrm{IrO}_{2}\right)$ ). Briefly, ISFET technology [38] appears as 
a valuable sensor owing to its response time and dynamic range. However, its measurement methodology is very different from electrochemical sensors. This may leads to the existence of current loss that disturb the platform measurements reliability ratability. The miniaturized ISE technique [39] represents a high risk related the formulation of the sensitive membrane leading to stability issues problems according to experiment duration. In this work, we use glass electrode as a reference method for $\mathrm{pH}$ measurements. However, its miniaturization for further implementation in a multiparametric $\mu$ fluidic platform is not possible. PANI [40-42] is a well-known semi-conductive polymer that has attracted attention in the scientific and engineering fields especially for application in chemical sensors and biosensors due to its easy preparation procedure. However, the formulation of PANI as an ink for screen-printing process, the long sensor response time [43] and the proteins adsorption properties of PANI membrane makes it here a mitigation plan for the $\mathrm{pH}$ sensor development $[43,44]$.

On the other hand, many studies have proven that hydrous $\mathrm{IrO}_{2}$ may be a good option for $\mathrm{pH}$ sensing using screen-printing or drop-casting technology [45-47] mainly for its biocompatibility, long-term stability and its rapid response $[48,49]$. For this purpose, $\mathrm{IrO}_{2}$ were examinated here as a $\mathrm{pH}$ redox material under flow rate conditions $\left(100 \mu \mathrm{L} \cdot \mathrm{min}^{-1}\right)$. Figure $3 \mathrm{a}$ shows the $\mathrm{pH}$ sensing response based on potentiometric measurements in PBS medium. The $\mathrm{pH}$ determination consists then on measuring the open circuit potential (OCP) between the $\mathrm{IrO}_{2}$ based carbon electrode and the reference electrode $(\mathrm{Ag} / \mathrm{AgCl})$. In such measurement methodology, the potential of the $\mathrm{pH}$ sensitive sensor is always measured at the equilibrium state. More particularly the $\mathrm{pH}$ response mechanism for the metal oxide electrodes is fundamentally different from that of traditional electrodes. In the case of $\mathrm{IrO}_{2}$ electrode, the $\mathrm{pH}$ response not only depends on the $\mathrm{H}^{+}$activity but also on the oxidation state of the iridium film. The equilibrium of iridium oxide electrode takes value of nearly $200 \mathrm{mV}$ vs $\mathrm{Ag} / \mathrm{AgCl}$ (Figure 3a) in PBS at $\mathrm{pH} 7.35$ suggesting that the $\mathrm{Ir} / \mathrm{V} / \mathrm{r} \mathrm{r}^{\mathrm{III}}$ couple is involved in the equilibrium as reported by Carroll et al. [50]. Thus, the redox reaction is given by the following equations either $\mathrm{IrO}_{x}$ is in its anhydrous or hydrous state $[50,51]$ :

$2 \mathrm{IrO}_{2}+2 \mathrm{H}^{+}+2 \mathrm{e}^{-} \longleftrightarrow \mathrm{Ir}_{2} \mathrm{O}_{3}+\mathrm{H}_{2} \mathrm{O}$ (for an anhydrous IrOx electrode)

$2\left[\mathrm{IrO}_{2}(\mathrm{OH})_{2} \cdot 2 \mathrm{H}_{2} \mathrm{O}\right]^{2-}+3 \mathrm{H}^{+}+2 \mathrm{e}^{-} \longleftrightarrow\left[\mathrm{Ir}_{2} \mathrm{O}_{3}(\mathrm{OH})_{3} \cdot 3 \mathrm{H}_{2} \mathrm{O}\right]^{3-}+3 \mathrm{H}_{2} \mathrm{O}$ (for the hydrated IrO $\mathrm{I}_{x}$ system)

Thus, the measured potential could be expressed using the following Nernst equations:

$E_{\text {Redox }}^{t h}=E_{0}^{I I V / I r^{I I I}}+\frac{R T}{2 F} \ln \left(\frac{a_{I r O 2}^{2} a_{H+}^{2}}{a_{I r 2 O 3}^{1}}\right)=E_{0}^{I I V} / I r^{I I I}+\frac{R T \ln \left(a_{H^{+}}^{2}\right)}{2 F}=E_{0}^{I r^{I V} / I r^{I I I}}-\frac{R T \ln (10)}{F} p H \quad$ (for an anhydrous IrO electrode)

$E_{\text {Redox }}^{t h}=E_{0}^{I I V / I r^{I I I}}+\frac{R T}{2 F} \ln \left(\frac{a_{I r O 2}^{2} a_{H+}^{3}}{a_{I r 2 O 3}^{1}}\right)=E_{0}^{r^{I V} / I r^{I I I}}+\frac{R T \ln \left(a_{H^{+}}^{3}\right)}{2 F}=E_{0}^{I r^{I V} / I r^{I I I}}-\frac{3 R T \ln (10)}{2 F} p H \quad$ (for the hydrated IrOx system)

Where $\mathrm{R}$ and $\mathrm{F}$ are respectively the perfect gas and the Faraday constants and $\mathrm{aH}_{+}$the activity of the hydronium ion. $E_{0}{ }^{1 \mathrm{IV} / \mathrm{Ir}^{\mathrm{III}}}$ is the standard potential of iridium oxide system. However, the later parameter generally slightly differs from the theoretical value due to experimental conditions (electrochemical cell architecture, medium...). Thereby; it is assimilated to an offset potential and determination of its value is of the first importance since it plays a role in the sensor calibration. Temporal shift of this offset potential gives some insights about the stability of the redox system in the conditions of use.

To calibrate the different sensors of the platform, PBS media of different pHs were flow through the microfluidic platform in function of time. In addition, this test was reproduced five times in order to establish five $\mathrm{pH}$-sensing cycles and to assess the reversibility and the reproducibility of the sensors responses. Indeed, between each cycle, the platform is washed with deionized water (the poor conductivity of the medium explaining the instability of the sensor response between two cycles). Nevertheless, the variation of the OCP $(\mathrm{mV})$ in function of $\mathrm{pH}$ is represented on Figure 3b. As expected, a linear relation $\left(\mathrm{r}^{2}>0.999\right)$ was observed with a slopes value corresponding to the sensitivity of $\mathrm{pH}$ sensor (between 56 and $58 \mathrm{mV} / \mathrm{pH}$ 
unit in absolute value). Thus, the experimental sensitivities were near ideal to the theoretical Nernstian slope ( $59 \mathrm{mV} / \mathrm{pH}$ unit). These results confirm that $\mathrm{IrO}_{2}$ probe was slightly affected by the hydrodynamic conditions.

Also, the sensors showed reversible responses as well as large dynamic range (here between 5 and 8) totally enough for the monitoring of $\mathrm{pH}$ needful for biological applications. The response time of sensors were of few seconds and remains quick stable during the $\mathrm{pH}$ sensing. According to the sensing sensitivity, the $\mathrm{pH}$ sensors demonstrated reproducible results for the different tests with acceptable Standard Deviation $(<5 \%)$. Moreover, an important feature deals with the fact that the iridium oxide film could be previously conditioned at a certain potential to fix its sensitivity. Such conditioning is somewhat easy to make through cyclic voltammetry and can be used to self-calibrate the $\mathrm{pH}$ sensor in case of drift. To conclude, iridium is an expensive material and its use may significantly increase the sensors platform cost regarding its production; however, the obtained results make it an option of choice in terms of technology selection and particularly relevant for the (bio)sensors platform development.

\section{2. $\quad \mathrm{H}_{2} \mathrm{O}_{2}$ sensing}

The development of hydrogen peroxide sensor is based on amperometric measurements. We proposed here to detect the hydrogen peroxide in reduction in order to avoid electrochemical interferences with the detection of $\mathrm{NO} / \mathrm{NO}_{2}-$. In fact, $\mathrm{H}_{2} \mathrm{O}_{2}$ detection is generally effected in oxidation at rather high potential at which $\mathrm{NO} / \mathrm{NO}_{2}$ could be detectable (as well as others electro-oxidizables species potentially present in the culture media). This strategy allows us to discriminate between amperometric responses of radical species $[52,53]$. Prussian blue (PB) is known to catalyze hydrogen peroxide reduction near to $0 \mathrm{~V} v s \mathrm{Ag} / \mathrm{AgCl}(-0.1 \mathrm{~V}$ $\pm 0.05 \mathrm{vs} \mathrm{Ag} / \mathrm{AgCl}$ ) and thus able to deliver electrochemical response free of interferences. Thereby, the detection of $\mathrm{H}_{2} \mathrm{O}_{2}$ by the $\mathrm{PB}$ modified carbon electrodes consists on the catalytic reduction of hydrogen peroxide on the Prussian blue interface (PB) according to the following reactions [54-56]:

$\mathrm{PB}_{\text {red }}+2 \mathrm{H}_{2} \mathrm{O}_{2} \longrightarrow \mathrm{PB}_{\mathrm{ox}}+4 \mathrm{OH}^{-} \quad$ (catalytic reaction)

$\mathrm{PB}_{\text {ox }}+4 \mathrm{e}^{-} \longleftrightarrow \mathrm{PB}_{\text {red }}$

(electrochemical regeneration of PB)

Figure 4a shows the voltammetric behavior of PB in PBS (1x) medium at a scan rate of $50 \mathrm{mV}^{-1} \mathrm{~s}^{-1}, 15$ cycles. The obtained voltammograms show the typical peaks usually observed for PB activation through successive cycling [57]. The reversible redox system of Prussian blue $\leftrightarrow$ Prussian white appears in the potential range of $-0.1-0 \mathrm{~V}$. Comparing to the literature, this system exhibits one pair of redox peaks in $1 \mathrm{M} \mathrm{KCl}[54,58]$. This is attributed to the higher concentration of background electrolyte (high concentration level of $\mathrm{K}^{+}$). At approx. $-0.3 \mathrm{~V}$, a pair of peaks is visible at the voltammogram and may corresponding to the electrochemical redox system of Ferri/Ferrocyanide ions in the bulk solution probably due to PB degradation during cycling. However, the catalytic activity of PB corresponding to the electrochemical oxidation/reduction of Prussian blue $\leftrightarrow$ Berlin green should appears at higher potentials range of $0.9-1.1 \mathrm{~V}$ in PBS (1x) medium (not visible at the voltammograms). It was in fact reported in the literature that the reduced form of Prussian Blue (also called Prussian White) had a catalytic effect for the reduction of $\mathrm{O}_{2}(\sim-0.3 \mathrm{~V})$ and hydrogen peroxide $(\sim 0$ V) [54]. Thus, the amperometric detection of $\mathrm{H}_{2} \mathrm{O}_{2}$ was realized by reduction at a potential of $-0.05 \mathrm{~V} v s$ $\mathrm{Ag} / \mathrm{AgCl}$, set nearly to the plateau of PW/PB reduction peak that enables selective reduction in presence of oxygen.

Figure $4 \mathrm{~b}$ shows the amperometric detection at $-0.05 \mathrm{~V} v s \mathrm{Ag} / \mathrm{AgCl}$ of hydrogen peroxide in PBS (1x) medium under flow rate conditions of $100 \mu \mathrm{L}$. $\mathrm{min}^{-1}$. Thus, the reductive current of $\mathrm{H}_{2} \mathrm{O}_{2}$ (iH2O2) increases with the $\mathrm{H}_{2} \mathrm{O}_{2}$ concentration. By plotting the variation of $\mathrm{i}_{\mathrm{H} 2 \mathrm{O}}=\mathrm{f}\left(\left[\mathrm{H}_{2} \mathrm{O}_{2}\right]\right)$ a linear relationship $\left(\mathrm{r}^{2}>0.99\right)$ is obtained with a slope value corresponding to the sensors sensitivity (average of $2.85 \mathrm{nA} / \mu \mathrm{M}$ ) (Fig. 4c). The obtained sensitivities of 5 sensors printed on the same platform are very close $(R S D=6.46 \%)$. These results highlight two important features. First, all the sensors exhibit similar responses whatever their position on the platform. This demonstrates that the flow, in the experimented conditions, does not differentially affect the electrochemical response of the sensors. Secondly, this shows that PB screen-printing process allows at obtaining reproducible catalytic behavior of the sensors toward hydrogen peroxide. The sensors show 
reversible responses as exemplified by the return to the same levels of response following flowing of solutions containing different concentration of $\mathrm{H}_{2} \mathrm{O}_{2}$ (Fig. 4b).

So far, the detection limit of hydrogen peroxide sensing under hydrodynamics conditions is estimated to few $\mu \mathrm{M}$ in PBS medium $(8 \pm 0.3 \mu \mathrm{M})$. On the other hand, the stability of PB ink over time was investigated. It was observed a sensitivity loss during long-sensing activity with the sensors. This result is probably due to the consumption of PB on the electrode interface over time especially in presence of high concentration of $\mathrm{H}_{2} \mathrm{O}_{2}$. Indeed, in these conditions, the generation of $\mathrm{OH}^{-}$leads to the local alkalization of the media despite the bulk solution buffering and to dissolution of PB in Ferri/Ferrocyanide ions [59]. Due to that limitation, two options are available to avoid the sensitivity loss: the first consists of realizing a sampling detection of hydrogen peroxide (e.g. 1 measurement point/hour) to minimize the consumption of PB of the electrode interface and stress less the electrode material. The second consists of establishing a one-point recalibration measurement during the hydrogen peroxide sensing (each 12 hours) to verify the sensitivity drift and correct the sensors signal according to the initial established calibration curve. For the second solution, the microfluidic cell-flow easily allows to realize this calibration using a dedicated by-pass channel. Nevertheless, the expected concentrations of $\mathrm{H}_{2} \mathrm{O}_{2}$ arising from cellular stress are rather low and thus the degradation of PB would not be such a problem.

\section{3. $\quad$ Nitric oxide sensing}

Nitric oxide (NO) is a very reactive compound with very short life-time of few sec at cell-culture temperature $(2-6 \mathrm{sec})[18,60]$. Its direct in situ measurement is thus complex. Therefore, complimentary strategy to asses indirectly the NO-secretions relies on the detection of the NO byproducts such as nitrite $\left(\mathrm{NO}_{2}^{-}\right)$[17]. In this work, we implemented this strategy since the (bio)sensors were developed as an external multiparametric platform.

Herein, $\mathrm{NO}_{2}{ }^{-}$was detected amperometrically owing to the use of catalyst (Meldola Blue) modifiedcarbon electrode [38]. By applying a potential of $+0.863 \mathrm{Vvs} \mathrm{Ag} / \mathrm{AgCl}, \mathrm{NO}_{2}$ - ions issued from $\mathrm{NO}$ secretions are electrochemically oxidized to $\mathrm{NO}_{3}{ }^{-}$at the electrode surface as follow $[61,62]$ :

$4 \mathrm{NO}+\mathrm{O}_{2}+2 \mathrm{H}_{2} \mathrm{O} \longrightarrow 4 \mathrm{H}^{+}+4 \mathrm{NO}_{2}^{-} \quad$ (homogenous-phase oxidation of $\mathrm{NO}$ in the cellculture medium)

$\mathrm{NO}_{2}^{-}+\mathrm{H}_{2} \mathrm{O} \longrightarrow \mathrm{NO}_{3}^{-}+2 \mathrm{H}^{+}+2 \mathrm{e}^{-} \quad$ (electrochemical oxidation of $\mathrm{NO}$ by-product)

Figure 5a shows the amperometric response of nitrite in PBS $(1 \mathrm{x}, \mathrm{pH} 7,4)$ medium under flow rate conditions $\left(100 \mu \mathrm{L} . \mathrm{min}^{-1}\right)$. As expected, the detection of $\mathrm{NO}_{2}-$ depends linearly on the concentration of the analyte (Fig. 5b). The sensor sensitivities are very close with an average value of $7.09 \pm 0.35$ $\mathrm{nA} / \mu \mathrm{M}(\mathrm{RSD}=5.02 \%)$. This highlights that screen-printing process allows at obtaining reproducible nitrite sensors. We also characterized the limit of detection of Meldola blue sensors under hydrodynamics conditions toward nitrite that takes value of around $2 \mu \mathrm{M}$ in PBS medium (data not shown). The sensors show reversible responses as exemplified by the return to the same levels of response following flowing of solutions containing different concentration of nitrite (Fig. 5b).

Otherwise, it is important to note that at this potential, hydrogen peroxide may be also detected by electrochemical oxidation. This may interfere on the NO measurement during the multiparametric detection strategy of the selected parameters. This aspect is more completely described in the following section devoted to multiparametric sensing (§ 3.5).

\subsection{Lactate sensing}

Lactate monitoring is effected using an amperometric enzymatic biosensor that embed the enzyme lactate oxidase (Lox). The current response is measured in reduction and arises from the two successive biochemical and electrochemical reactions [63]: 
L-Lactate $+\mathrm{O}_{2} \longrightarrow$ Pyruvate $+\mathrm{H}_{2} \mathrm{O}_{2}$

(enzymatic biofilm)

$\mathrm{PB}_{\text {red }}+2 \mathrm{H}_{2} \mathrm{O}_{2} \longrightarrow \mathrm{PB}_{\text {ox }}+4 \mathrm{OH}^{-}$

(catalytic surface reaction)

$\mathrm{PB}_{\text {ox }}+4 \mathrm{e}^{-} \longleftrightarrow \mathrm{PB}_{\text {red }}$

(electrochemical regeneration of PB)

The lactate is catalyzed by the lactate oxidase (Lox) generating pyruvate and hydrogen peroxide $\left(\mathrm{H}_{2} \mathrm{O}_{2}\right)$ as by-products. Peroxide molecules that are able to diffuse the electrode surface through the enzymatic biofilm are further reduced on the Prussian blue interface as already described in the hydrogen peroxide detection section (§3.2).

Therefore, the measured reductive current via the transducer interface is used for the lactate monitoring. Figure 6 a shows the amperometric response of the lactate biosensors (potential of -0.05 $\mathrm{V} v s \mathrm{Ag} / \mathrm{AgCl})$ in PBS $(1 \mathrm{x}, \mathrm{pH} 7,4)$ medium under flow rate conditions $\left(100 \mu \mathrm{L} \cdot \mathrm{min}^{-1}\right)$. The current response is then proportional to the L-lactate concentrations (Fig. 6b) with an average sensitivity of $0.87 \pm 0.08 \mathrm{nA} / \mu \mathrm{M}$ (RSD $9.97 \%$ ). One can notice the relative dispersion of calibration curves obtained for the five sensors. Indeed, this come from the biofilm deposition on the PB electrode that is currently under optimization process to obtain a better reproducibility. The Fig. 6a highlights the nice reversibility of the lactate biosensors in the lactate concentration range $(50-500 \mu \mathrm{M})$. Indeed, the dynamic range of the lactate biosensors is larger (up to $3 \mathrm{mM}$ ). However, at higher concentration range of lactate $(>1 \mathrm{mM})$, the biosensors exhibit rapid degradation profile due the alkalization of the electrode interface generated by the hydrogen peroxide reduction as already mentioned [64]. Otherwise, we also characterized the limit of detection of lactate biosensors under hydrodynamics conditions $\left(100 \mu \mathrm{L} \cdot \mathrm{min}^{-1}\right)$ that takes value of around $20 \mu \mathrm{M}$ in PBS medium.

\subsection{Multiparametric sensing configuration}

From an experimental point of view, sensing in a multiparametric configuration is more complex than sensing an individual parameter because of interfering and cross-talk signals that may be encountered [65]. Indeed, in terms of interferences, as already mentioned endogenous hydrogen peroxide may be detected on the nitrite and the lactate sensors. As well, lactate may influence the $\mathrm{pH}$ of the measured media. Otherwise, lactate oxidase encapsulated at the surface of the lactate sensor generates some exogenous hydrogen peroxide that could be detected on the $\mathrm{H}_{2} \mathrm{O}_{2}$ and nitrite sensors. In this configuration, the response of the sensors should be correlated in order to extract the specific metabolites concentrations from the raw data. Moreover, the positioning of the sensors on the platform has to be selected according to the flux inside the flow-cell to limit crosstalk signals.

Herein, 8 working electrodes were modified by pairs using the different sensitive layers as already described. Thereby, the lactate sensors are positioned near to the outlet of the flow-cell (position 5 and 6) to avoid cross-talk with the other sensors. The other sensors are placed in the remaining positions: $\mathrm{H}_{2} \mathrm{O}_{2}$ sensors are placed in position 1 and 2 while $\mathrm{pH}$ sensor are placed at position 3 and 4 and $\mathrm{NO} / \mathrm{NO}_{2}-$ sensors are placed respectively at position 7 and 8 .

During measurements, the responses were simultaneously recorded potentiometrically for $\mathrm{pH}$ sensors and amperometrically for the hydrogen peroxide, nitrite and lactate sensors that are polarized at respective potentials of $-0.05,+0.863$ and $-0.05 \mathrm{~V} v s \mathrm{Ag} / \mathrm{AgCl}$. Figure 7 shows the raw amperometric responses of these sensors.

As illustrated, during nitrite injection (step 1) only $\mathrm{NO} / \mathrm{NO}_{2}-$ sensors (MB) shows a signal evolution $\left(830 \mathrm{nA} / 100 \mu \mathrm{M} \mathrm{NO}{ }^{-}\right)$. Besides this, the other sensors signals are stable demonstrating that no interferences or competitive reactions occurs in this case. Also, a similar behavior is observed during lactate injection (step 2) where only lactate sensors (PB/Lox) show signal evolutions (125 nA / 250 $\mu \mathrm{M}$ lactate). As expected, the generated hydrogen peroxide species in the detection process of 
lactate does not affect the hydrogen peroxide and the nitrite sensors due to the position of lactate sensor near the outlet of the $\mu$ fluidic chamber.

However, during $\mathrm{H}_{2} \mathrm{O}_{2}$ injection (step 3) all amperometric sensors display a current evolution. Comparing between the responses of lactate and hydrogen peroxide sensors, both sensors showed a very close current evolution (approx. $350 \mathrm{nA} / 100 \mu \mathrm{M} \mathrm{H}_{2} \mathrm{O}_{2}$ ). This indicates that injected $\mathrm{H}_{2} \mathrm{O}_{2}$ species were amperometrically reduced at the Prussian blue surface of sensors $1 \& 2$ and traversing the (bio)enzymatic membrane of lactate sensors to be also reduced through the Prussian blue interface of sensors $5 \& 6$. In addition, the current evolution of sensors $7 \& 8$ demonstrates that $\mathrm{H}_{2} \mathrm{O}_{2}$ species were amperometrically oxidized at the Meldola blue surface. Nevertheless, C. Amatore et al.[66-68] have already reported the strategy of electrochemical data processing in the case of a multiparametric sensing configuration considering of precisely determining the current of different detected species electrochemically as follow [69,70]:

$$
i_{\text {cell }}^{E}=\left(a \times i_{1}^{E}\right)+\left(b \times i_{2}^{E}\right)+\sum n\left(x \times i_{n}^{E}\right)
$$

where $i_{\text {cell }}^{E}$ is the measured current at any given potential, $E$, for the detected species $(1,2 \ldots n)$ on the electrode material and, $a, b \ldots x$ are the relative fixed coefficients related to the reference concentrations.

Based on the result of Figure 7, complementary measurements were separately conducted to evaluate the coefficients quantifying the concentration of the detected species at the given potentials. Figure 8 shows the comparison between the sensing sensitivity of hydrogen peroxide on different electrode materials of Meldola blue (at $+0.863 \mathrm{~V}$ ) and Prussian blue (at $-0.05 \mathrm{~V}$ ). As illustrated, the obtained experimental values show that sensors have different sensitivities for $\mathrm{H}_{2} \mathrm{O}_{2}$ detection. The ratio of the obtained values $0.36(1.03 / 2.85)$ is corresponding to the selectivity coefficient of $\mathrm{H}_{2} \mathrm{O}_{2}$ in the case of multiparametric sensing configuration and conducting to determine the relationships given below:

$$
\begin{aligned}
& i_{1 \& 2}=i_{\mathrm{H}_{2} \mathrm{O}_{2}} \text { at } E=-0.05 \mathrm{~V} / \mathrm{REF} \\
& i_{7 \& 8}=i_{\mathrm{NO}_{2}}-0.36 i_{\mathrm{H}_{2} \mathrm{O}_{2}} \text { at } E=+0.863 \mathrm{~V} / \mathrm{REF}
\end{aligned}
$$

Also, the current evolution of lactate and $\mathrm{H}_{2} \mathrm{O}_{2}$ sensors during $\mathrm{H}_{2} \mathrm{O}_{2}$ injection (Fig. 7a) showed a similar current values $(350 \mathrm{nA} / 100 \mu \mathrm{M})$ conducting to conclude the following relationship:

$$
i_{5 \& 6}=i \text { Lactate }+i_{\mathrm{H}_{2} \mathrm{O}_{2}} \text { at } E=-0.05 \mathrm{~V} / \mathrm{REF}
$$

For the potentiometric measurements of $\mathrm{pH}$ (sensors $3 \& 4$ ), the $\mathrm{pH}$ electrodes responses rapidly stabilize following nitrite and $\mathrm{H}_{2} \mathrm{O}_{2}$ injection (steps $1 \& 3$ ). However, lactate injection (step 2) induces a mark shift in the $\mathrm{pH}$ sensors responses as illustrated by the potential increase (Fig. 7b). This is due to the acidification of the medium by lactate.

\subsection{Ex-situ characterization of cell culture media by the biosensing platform}

To illustrate the use of biosensing platform, we assessed its electrochemical response in real solutions collected from cell-culture. Therefore, we carried out the ex-situ testing of samples coming from culturing a human colorectal adenocarcinoma cell line i.e. Caco- 2 cells (refer to $\S 2.5$ for culture conditions). During the cell-culture, the medium was replaced every 2-3 days. After 21 days, in order to mimic a stress behaviour, the cells were continuously exposed to SDS solution $0.5 \mathrm{mM}$ for 24 hours. In fact, SDS is known to induce the degradation of tight junctions leading to stress and to final apoptosis of the Caco-2 cells [71]. In these conditions, the cells are known to express the stress metabolites that could be measured by the multiparametric platform. After SDS exposure the media was collected and used for analysis on the multiparametric (bio)sensing platform. Samples without SDS exposure were used as control for this experiment.

Figure 9 shows the results obtained for the ex-situ characterization of the cell-culture media by the biosensing platform. As expected, one can observe a clear increase of lactate, hydrogen peroxide and $\mathrm{NO} / \mathrm{NO}_{2}{ }^{-}$concentrations after exposure to SDS. Concomitantly, slight decrease in $\mathrm{pH}$ is 
observed $(\Delta \mathrm{pH}=0.16)$. The relatively small drop in the $\mathrm{pH}$ is not surprising since the culture media contains a strong buffer (i.e., Earle's salts and sodium bicarbonate).

The detection of these metabolites confirm the stress of the cells due to the exposure to SDS. Moreover, diacidification of the culture medium can be explained by the lactate production that occurs under hypoxic conditions. Consequently, glycolysis of proliferating cells which conduct to the media pH evolution [72].

Herein, we demonstrated that this modular set-up provides a powerful toolkit for the detection of metabolites issued from the inflammatory process for in vitro testing.

\section{CONCLUSIONS}

The development of an original electrochemical (bio)sensing platform for real-time monitoring of a selected cellular metabolites is reported. The design and the qualification of this sensors platform was studied and carried out in artificial medium. In this study, we demonstrate that applying our design and our fabrication strategy of this platform enables the detection of multiple parameters involved in the cell culture stress. The 3D design of the technological approaches for the aggregation of the different sensors on the $\mu$ fluidic platform also called fluidic circuit board (FCB) is presented on Figure 10. The proposed FCB design is developed using building blocks modules strategy and containing principally 3 modules: cell-culture chamber with impedance sensor module optically compatible in case of microscope utilization, integrated peristaltic pump module reducing the deadvolume and; the multiparametric (bio)sensing chamber module. Thereby, the nature of the sensed parameters could be modulated to allow monitoring of cell cultures involved in different applications such as drug screening or organ-on-chip.

\section{CONFLICT OF INTEREST STATMENT}

There are no conflicts to declare.

\section{ACKNOWLEDGEMENTS}

PANBioRA project has received funding from the European Union's Horizon 2020 research and innovation program under grant agreement No 760921.

\section{REFERENCES}

[1] P. Kassanos, F. Seichepine, D. Wales, G.Z. Yang, Towards a Flexible/Stretchable Multiparametric Sensing Device for Surgical and Wearable Applications, Biomed. Circuits Syst. Conf. Proc. (2019) 1-4. https://doi.org/10.1109/BIOCAS.2019.8919197.

[2] Y.G.-Z. Anastasova Salzitsa, Kassanos Panagiotis, Multi-parametric rigid and flexible, low-cost, disposable sensing platforms for biomedica applications, Biosens. Bioelectron. 102 (2018) 668675.

[3] Y. Eminaga, M. Brischwein, H. Grothe, Multiparametric Microsensors on Labonchip Systems for the Detection of Dissolved Substances, Proc. IMCS 2012. 396 (2012) 316-318. https://doi.org/10.5162/IMCS2012/3.5.4.

[4] H.H. Huynh Tan-Phat, Self-Healing, Fully Functionnal, and Multiparametric Flexible Sensing Platform, Adv. Mater. 28 (2016) 138-143. https://doi.org/10.1002/adma.201504104.

[5] B. Zhang, A. Korolj, B.F.L. Lai, M. Radisic, Advances in organ-on-a-chip engineering, Nat. Rev. Mater. 3 (2018) 2018. https://doi.org/10.1038/s41578-018-0034-7. 
[6] A. Skardal, S. V. Murphy, M. Devarasetty, I. Mead, H.W. Kang, Y.J. Seol, Y.S. Zhang, S.R. Shin, L. Zhao, J. Aleman, A.R. Hall, T.D. Shupe, A. Kleensang, M.R. Dokmeci, S. Jin Lee, J.D. Jackson, J.J. Yoo, T. Hartung, A. Khademhosseini, S. Soker, C.E. Bishop, A. Atala, Multi-tissue interactions in an integrated three-tissue organ-on-a-chip platform, 2017. https://doi.org/10.1038/s41598-01708879-x.

[7] F. Liu, A.N. Nordin, I. Voiculescu, Multiparametric MEMS biosensor for cell culture monitoring, 2013 Symp. Des. Test, Integr. Packag. MEMS/MOEMS, DTIP 2013. (2013) 1-5.

[8] T. Geisler, J. Ressler, H. Harz, B. Wolf, R. Uhl, Automated multiparametric platform for highcontent and high-throughput analytical screening on living cells, IEEE Trans. Autom. Sci. Eng. 3 (2006) 169-176. https://doi.org/10.1109/TASE.2006.871476.

[9] C. Ress, A. Adami, L. Lorenzelli, C. Collini, A. Tindiani, A. Maglione, G. Soncini, Development and characterization of a multiparametric microsensor for yeast cell growth monitoring, Procedia Chem. 1 (2009) 1059-1062. https://doi.org/10.1016/j.proche.2009.07.264.

[10] E.B.W. Shang Wu, Chen Chen-Yu, Lo Kimberly, F. Payne Gregory, Chip mudularity enables molecular information acess from organ-on-chip devices with quality control, Sensors Actuators, B Chem. 295 (2019) 30-39.

[11] Y.S. Zhang, J. Aleman, S.R. Shin, T. Kilic, D. Kim, S.A.M. Shaegh, S. Massa, R. Riahi, S. Chae, N. Hu, H. Avci, W. Zhang, A. Silvestri, A.S. Nezhad, A. Manbohi, F. De Ferrari, A. Polini, G. Calzone, N. Shaikh, P. Alerasool, E. Budina, J. Kang, N. Bhise, J. Ribas, A. Pourmand, A. Skardal, T. Shupe, C.E. Bishop, M.R. Dokmeci, A. Atala, A. Khademhosseini, Multisensor-integrated organs-on-chips platform for automated and continual in situ monitoring of organoid behaviors, Proc. Natl. Acad. Sci. U. S. A. 114 (2017) E2293-E2302. https://doi.org/10.1073/pnas.1612906114.

[12] M.J. Anderson, R. Analiz, T.C. David, Foreign body reaction to biomaterials, Semin. Immunol. 20 (2008) 86-100.

[13] D.M. Wong, R.M. Moore, C.W. Brockus, Mechanisms of oxidative injury in equine disease, Compend. Contin. Educ. Vet. 34 (2012) 1-8.

[14] M.C. Regier, S.I. Montanez-Sauri, M.P. Schwartz, W.L. Murphy, D.J. Beebe, K.E. Sung, The Influence of Biomaterials on Cytokine Production in 3D Cultures, Biomacromolecules. 18 (2017) 709-718. https://doi.org/10.1021/acs.biomac.6b01469.

[15] M. Tovar, L. Mahler, S. Buchheim, M. Roth, M.A. Rosenbaum, Monitoring and external control of $\mathrm{pH}$ in microfluidic droplets during microbial culturing, Microb. Cell Fact. 19 (2020) 1-9. https://doi.org/10.1186/s12934-020-1282-y.

[16] J.R. Casey, S. Grinstein, J. Orlowski, Sensors and regulators of intracellular pH, Nat. Rev. Mol. Cell Biol. 11 (2010) 50-61. https://doi.org/10.1038/nrm2820.

[17] Hetrick M. Evan, S.H. Mark, Analytical Chemistry of Nitric Oxide, Annu. Rev. Anal. Chem. 3 (2009) 409-433. https://doi.org/10.1038/jid.2014.371.

[18] A. Chmayssem, K. Monsalve-Grijalba, M. Alias, V. Mourier, S. Vignoud, L. Scomazzon, C. Muller, J. Barthes, N.E. Vrana, P. Mailley, Reference method for off-line analysis of nitrogen oxides in cell culture media by an ozone-based chemiluminescence detector, Anal. Bioanal. Chem. (2021) (accepted manuscript). https://doi.org/10.1007/s00216-020-03102-9. 
[19] N.E. Luiking, Yvette C; Engelen, Mariëlle PKJ; Deutz, Regulation of Nitric Oxide production in health and disease, Curr. Opin. Clin. Nutr. Metab. Care. 13 (2011) 97-104. https://doi.org/10.1097/MCO.0b013e328332f99d.REGULATION.

[20] J. Zhang, Y. Fu, P. Yang, X. Liu, Y. Li, Z. Gu, ROS Scavenging Biopolymers for Anti-Inflammatory Diseases: Classification and Formulation, Adv. Mater. Interfaces. (2020). https://doi.org/10.1002/admi.202000632.

[21] I.S. Harris, G.M. DeNicola, The Complex Interplay between Antioxidants and ROS in Cancer, Trends Cell Biol. 30 (2020) 440-451. https://doi.org/10.1016/j.tcb.2020.03.002.

[22] C. Calas-Blanchard, G. Catanante, T. Noguer, Electrochemical Sensor and Biosensor Strategies for ROS/RNS Detection in Biological Systems, Electroanalysis. 26 (2014) 1277-1286. https://doi.org/10.1002/elan.201400083.

[23] L. Rassaei, W. Olthuis, S. Tsujimura, E.J.R. Sudhölter, A. Van Den Berg, Lactate biosensors: Current status and outlook, Anal. Bioanal. Chem. 406 (2014) 123-137. https://doi.org/10.1007/s00216013-7307-1.

[24] M.D. Brown, M.H. Schoenfisch, Electrochemical Nitric Oxide Sensors: Principles of Design and Characterization, Chem. Rev. 119 (2019) 11551-11575. https://doi.org/10.1021/acs.chemrev.8b00797.

[25] A. Weltin, B. Enderle, J. Kieninger, G.A. Urban, Multiparametric, flexible microsensor platform for metabolic monitoring in vivo, IEEE Sens. J. 14 (2014) 3345-3351. https://doi.org/10.1109/JSEN.2014.2323220.

[26] J. Shi, L. Tong, W. Tong, H. Chen, M. Lan, X. Sun, Y. Zhu, Current progress in long-term and continuous cell metabolite detection using microfluidics, TrAC - Trends Anal. Chem. 117 (2019) 263-279. https://doi.org/10.1016/j.trac.2019.05.028.

[27] E. Witkowska Nery, E. Jastrzebska, K. Zukowski, W. Wróblewski, M. Chudy, P. Ciosek, Flowthrough sensor array applied to cytotoxicity assessment in cell cultures for drug-testing purposes, Biosens. Bioelectron. 51 (2014) 55-61. https://doi.org/10.1016/j.bios.2013.07.023.

[28] J.L. House, E.M. Anderson, W.K. Ward, Immobilization techniques to avoid enzyme loss from oxidase-based biosensors: A one-year study, J. Diabetes Sci. Technol. 1 (2007) 18-27. https://doi.org/10.1177/193229680700100104.

[29] M.R. Romero, F. Garay, A.M. Baruzzi, Design and optimization of a lactate amperometric biosensor based on lactate oxidase cross-linked with polymeric matrixes, Sensors Actuators, B Chem. 131 (2008) 590-595. https://doi.org/10.1016/j.snb.2007.12.044.

[30] N. Vasylieva, S. Marinesco, Enzyme immobilization on microelectrode biosensors, 2013. https://doi.org/10.1007/978-1-62703-370-1-5.

[31] S. Marinesco, O. Frey, Microelectrode designs for oxidase-based biosensors, 2013. https://doi.org/10.1007/978-1-62703-370-1-1.

[32] R.B. Shah, A. Palamakula, M.A. Khan, Cytotoxicity Evaluation of Enzyme Inhibitors and Absorption Enhancers in Caco-2 Cells for Oral Delivery of Salmon Calcitonin, J. Pharm. Sci. 93 (2004) 10701082. https://doi.org/10.1002/jps.20007.

[33] E. Haltner-Ukomadu, S. Gureyeva, O. Burmaka, A. Goy, L. Mueller, G. Kostyuk, V. Margitich, In 
vitro bioavailability study of an antiviral compound enisamium iodide, Sci. Pharm. 86 (2018) 1-10. https://doi.org/10.3390/scipharm86010003.

[34] E.T.M. S.C. Mailley, M. Hyland, P. Mailley, J.M. McLaughlin, Electrochemical and structural characterizations of electrodepositediridium oxide thin-film electrodes applied to neurostimulatingelectrical signal, Mater. Sci. Eng. C. 21 (2002) 167-175.

[35] Z. Chu, Y. Liu, W. Jin, Recent progress in Prussian blue films: Methods used to control regular nanostructures for electrochemical biosensing applications, Biosens. Bioelectron. 96 (2017) 1725. https://doi.org/10.1016/j.bios.2017.04.036.

[36] G. Scheiblin, A. Aliane, X. Strakosas, V.F. Curto, R. Coppard, G. Marchand, R.M. Owens, P. Mailley, G.G. Malliaras, Screen-printed organic electrochemical transistors for metabolite sensing, MRS Commun. 5 (2015) 507-511. https://doi.org/10.1557/mrc.2015.52.

[37] L. Manjakkal, D. Szwagierczak, R. Dahiya, Metal oxides based electrochemical pH sensors: Current progress and future perspectives, Prog. Mater. Sci. 109 (2020) 100635.

https://doi.org/10.1016/j.pmatsci.2019.100635.

[38] A. Vasilescu, S. Andreescu, C. Bala, S. Carmen Litescu, N. Thierry, M. Jean-Louis, Screen-printed electrodes with electropolymerized Meldola Blue asversatile detectors in biosensors, Biosens. Bioelectron. 18 (2003) 781-790.

[39] R. De Marco, G. Clarke, B. Pejcic, lon-selective electrode potentiometry in environmental analysis, Electroanalysis. 19 (2007) 1987-2001. https://doi.org/10.1002/elan.200703916.

[40] S.L. Ulrich-W. Grummt, Adam Pron, Malgorzata Zagorska, Polyaniline based optical pH sensor, Anal. Chim. Acta. 357 (1997) 253-259.

[41] J.H. Yoon, S.B. Hong, S.O. Yun, S.J. Lee, T.J. Lee, K.G. Lee, B.G. Choi, High performance flexible pH sensor based on polyaniline nanopillar array electrode, J. Colloid Interface Sci. 490 (2017) 53-58. https://doi.org/10.1016/j.jcis.2016.11.033.

[42] R. Rahimi, M. Ochoa, T. Parupudi, X. Zhao, I.K. Yazdi, M.R. Dokmeci, A. Tamayol, A. Khademhosseini, B. Ziaie, A low-cost flexible pH sensor array for wound assessment, Sensors Actuators, B Chem. 229 (2016) 609-617. https://doi.org/10.1016/j.snb.2015.12.082.

[43] G. Scheiblin, R. Coppard, R.M. Owens, P. Mailley, G.G. Malliaras, Referenceless pH Sensor using Organic Electrochemical Transistors, Adv. Mater. Technol. 2 (2017) 1-5. https://doi.org/10.1002/admt.201600141.

[44] D. Gosselin, M. Gougis, M. Baque, F.P. Navarro, M.N. Belgacem, D. Chaussy, A.G. Bourdat, P. Mailley, J. Berthier, Screen-Printed Polyaniline-Based Electrodes for the Real-Time Monitoring of Loop-Mediated Isothermal Amplification Reactions, Anal. Chem. 89 (2017) 10124-10128. https://doi.org/10.1021/acs.analchem.7b02394.

[45] Q. Dong, D. Song, Y. Huang, Z. Xu, J.H. Chapman, W.S. Willis, B. Li, Y. Lei, High-temperature annealing enabled iridium oxide nanofibers for both non-enzymatic glucose and solid-state $\mathrm{pH}$ sensing, Electrochim. Acta. 281 (2018) 117-126. https://doi.org/10.1016/j.electacta.2018.04.205.

[46] Q. Dong, Dual functional rhodium oxide nanocorals enabled sensor for both non-enzymatic glucose and solid-state pH sensing, 2018. https://doi.org/10.1016/j.bios.2018.04.021.

[47] Q. Dong, Y. Huang, D. Song, H. Wu, F. Cao, Y. Lei, Dual functional rhodium oxide nanocorals 
enabled sensor for both non-enzymatic glucose and solid-state $\mathrm{pH}$ sensing, Biosens. Bioelectron. 112 (2018) 136-142. https://doi.org/10.1016/j.bios.2018.04.021.

[48] Q. Dong, D. Song, Y. Huang, Z. Xu, J.H. Chapman, W.S. Willis, B. Li, Y. Lei, High-temperature annealing enabled iridium oxide nanofibers for both non-enzymatic glucose and solid-state $\mathrm{pH}$ sensing, Electrochim. Acta. 281 (2018) 117-126. https://doi.org/10.1016/j.electacta.2018.04.205.

[49] W.D. Huang, H. Cao, S. Deb, M. Chiao, J.C. Chiao, A flexible pH sensor based on the iridium oxide sensing film, Sensors Actuators, A Phys. 169 (2011) 1-11.

https://doi.org/10.1016/j.sna.2011.05.016.

[50] S. Carroll, R.P. Baldwin, Self-calibrating microfabricated iridium oxide pH electrode array for remote monitoring, Anal. Chem. 82 (2010) 878-885. https://doi.org/10.1021/ac9020374.

[51] P.S. Dittrich, K. Tachikawa, A. Manz, Micro total analysis systems. Latest advancements and trends, Anal. Chem. 78 (2006) 3887-3907. https://doi.org/10.1021/ac0605602.

[52] S.F. Peteu, R. Boukherroub, S. Szunerits, Nitro-oxidative species in vivo biosensing: Challenges and advances with focus on peroxynitrite quantification, Biosens. Bioelectron. 58 (2014) 359-373. https://doi.org/10.1016/j.bios.2014.02.025.

[53] R. Oliveira, C. Sella, C. Souprayen, E. Ait-Yahiatene, C. Slim, S. Griveau, L. Thouin, F. Bedioui, Development of a flow microsensor for selective detection of nitric oxide in the presence of hydrogen peroxide, Electrochim. Acta. 286 (2018) 365-373.

https://doi.org/10.1016/j.electacta.2018.07.158.

[54] A.A. Karyakin, Prussian Blue and Its Analogues: Electrochemistry and Analytical Applications, Electroanalysis. 13 (2001) 813-819.

[55] A.A. Karyakin, E.E. Karyakina, Prussian blue-based "artificial peroxidase" as a transducer for hydrogen peroxide detection. Application to biosensors, Sensors Actuators, B Chem. 57 (1999) 268-273. https://doi.org/10.1016/S0925-4005(99)00154-9.

[56] J.L. Lyon, K.J. Stevenson, Picomolar peroxide detection using a chemically activated redox mediator and square wave voltammetry, Anal. Chem. 78 (2006) 8518-8525. https://doi.org/10.1021/ac061483d.

[57] F. Ricci, G. Palleschi, Sensor and biosensor preparation, optimisation and applications of Prussian Blue modified electrodes, Biosens. Bioelectron. 21 (2005) 389-407. https://doi.org/10.1016/j.bios.2004.12.001.

[58] A.A. Karyakin, E.E. Karyakina, L. Gorton, On the mechanism of $\mathrm{H} 2 \mathrm{O} 2$ reduction at Prussian Blue modified electrodes, Electrochem. Commun. 1 (1999) 78-82. https://doi.org/10.1016/S13882481(99)00010-7.

[59] R.I. Gearba, M. Kim, K.M. Mueller, P.A. Veneman, K. Lee, B.J. Holliday, C.K. Chan, J.R. Chelikowsky, E. Tutuc, K.J. Stevenson, Atomically Resolved Elucidation of the Electrochemical Covalent Molecular Grafting Mechanism of Single Layer Graphene, Adv. Mater. Interfaces. 3 (2016) 1-10. https://doi.org/10.1002/admi.201600196.

[60] M. Kelm, Nitric oxide metabolism and breakdown, Biochim. Biophys. Acta - Bioenerg. 1411 (1999) 273-289. https://doi.org/10.1016/S0005-2728(99)00020-1.

[61] T.L. Broder, D.S. Silvester, L. Aldous, C. Hardacre, R.G. Compton, Electrochemical oxidation of 
nitrite and the oxidation and reduction of $\mathrm{NO} 2$ in the room temperature ionic liquid [C2mim][NTf2], J. Phys. Chem. B. 111 (2007) 7778-7785. https://doi.org/10.1021/jp0728104.

[62] S.-W. Roh, J.R. Stetter, Gold Film Amperometric Sensors for NO and NO2, J. Electrochem. Soc. 150 (2003) 272-277. https://doi.org/10.1149/1.1616003.

[63] B.M. Lowinsohn Denise, Flow injection analysis of bloodL-lactate by using a PrussianBlue-based biosensor as amperometric detector, Anal. Biochem. 265 (2007) 260-265.

[64] J.M. Noël, J. Médard, C. Combellas, F. Kanoufi, Prussian Blue Degradation during Hydrogen Peroxide Reduction: A Scanning Electrochemical Microscopy Study on the Role of the Hydroxide Ion and Hydroxyl Radical, ChemElectroChem. 3 (2016) 1178-1184. https://doi.org/10.1002/celc.201600196.

[65] P. Giménez-Gómez, R. Rodríguez-Rodríguez, J.M. Ríos, M. Pérez-Montero, E. González, M. Gutiérrez-Capitán, J.A. Plaza, X. Muñoz-Berbel, C. Jiménez-Jorquera, A self-calibrating and multiplexed electrochemical lab-on-a-chip for cell culture analysis and high-resolution imaging, Lab Chip. 20 (2020) 823-833. https://doi.org/10.1039/c9lc01051c.

[66] Y. Li, A. Meunier, R. Fulcrand, C. Sella, C. Amatore, L. Thouin, F. Lemaître, M. Guille-Collignon, Multi-chambers Microsystem for Simultaneous and Direct Electrochemical Detection of Reactive Oxygen and Nitrogen Species Released by Cell Populations, Electroanalysis. 28 (2016) 1865-1872. https://doi.org/10.1002/elan.201501157.

[67] Y. Li, C. Sella, F. Lemaître, M. GuilleCollignon, L. Thouin, C. Amatore, Highly Sensitive PlatinumBlack Coated Platinum Electrodes for Electrochemical Detection of Hydrogen Peroxide and Nitrite in Microchannel, Electroanalysis. 25 (2013) 895-902. https://doi.org/10.1002/elan.201200456.

[68] C. Lu, J.M. Heldt, M. Guille-Collignon, F. Lemaître, G. Jaouen, A. Vessières, C. Amatore, Quantitative analyses of ROS and RNS production in breast cancer cell lines incubated with ferrocifens, ChemMedChem. 9 (2014) 1286-1293. https://doi.org/10.1002/cmdc.201402016.

[69] C. Amatore, S. Arbault, C. Bouton, K. Coffi, J.C. Drapier, H. Ghandour, Y. Tong, Monitoring in real time with a microelectrode the release of reactive oxygen and nitrogen species by a single macrophage stimulated by its membrane mechanical depolarization, ChemBioChem. 7 (2006) 653-661. https://doi.org/10.1002/cbic.200500359.

[70] Y. Li, C. Sella, F. Lemaître, M. Guille-Collignon, L. Thouin, C. Amatore, Electrochemical detection of nitric oxide and peroxynitrite anion in microchannels at highly sensitive platinum-black coated electrodes. application to ROS and RNS mixtures prior to biological investigations, Electrochim. Acta. 144 (2014) 111-118. https://doi.org/10.1016/j.electacta.2014.08.046.

[71] E.K. Anderberg, P. Artursson, Epithelial transport of drugs in cell culture. VIII: Effects of sodium dodecyl sulfate on cell membrane and tight junction permeability in human intestinal epithelial (Caco-2) cells, J. Pharm. Sci. 82 (1993) 392-398. https://doi.org/10.1002/jps.2600820412.

[72] H.C. Bygd, K.D. Forsmark, K.M. Bratlie, The significance of macrophage phenotype in cancer and biomaterials, Clin. Transl. Med. 3 (2014) 1-13. https://doi.org/10.1186/s40169-014-0041-2. 

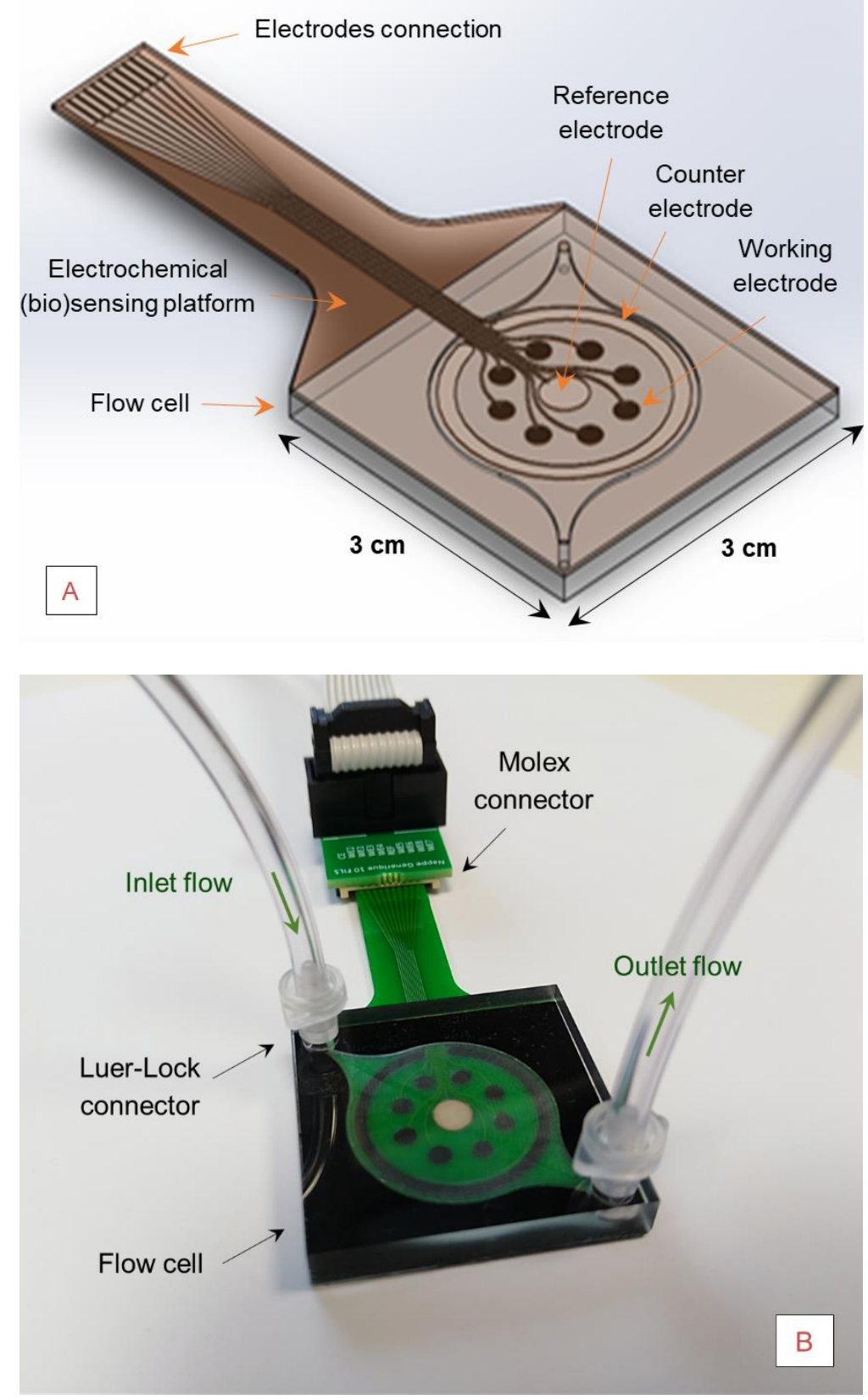

Fig. 1. (a) 3D design of the electrochemical (bio)sensing platform embedded in the flow cell. (b) The electrochemical (bio)sensing platform electrically connected using Molex connector and $\mu$ fluidically connected to the flow cell using luer lock connector. 


\section{Carbon-based ink $+\mathrm{IrO}_{2}$}

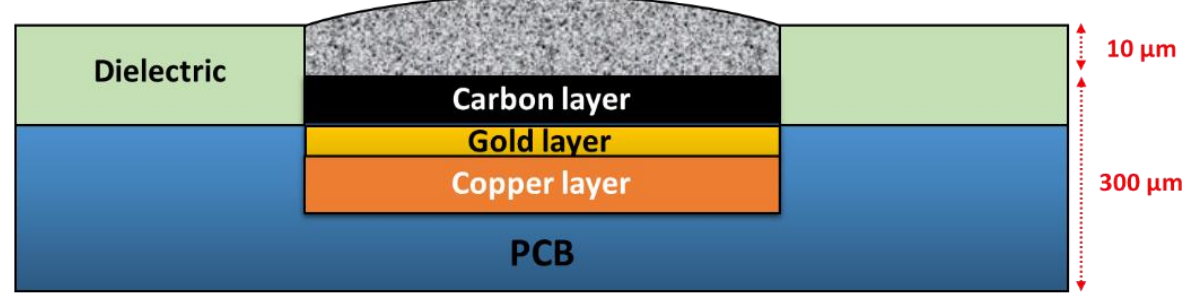

pH sensor

b

Carbon-based

Prussian blue paste

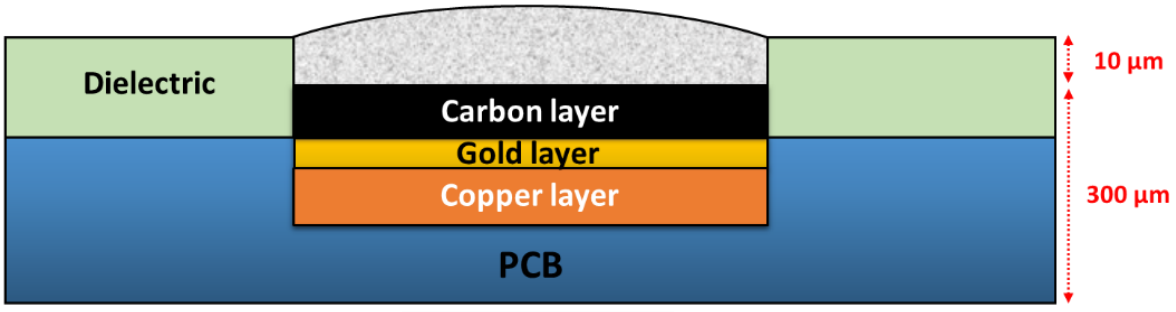

$\mathrm{H}_{2} \mathrm{O}_{2}$ sensor

c Carbon-based

Meldola blue paste

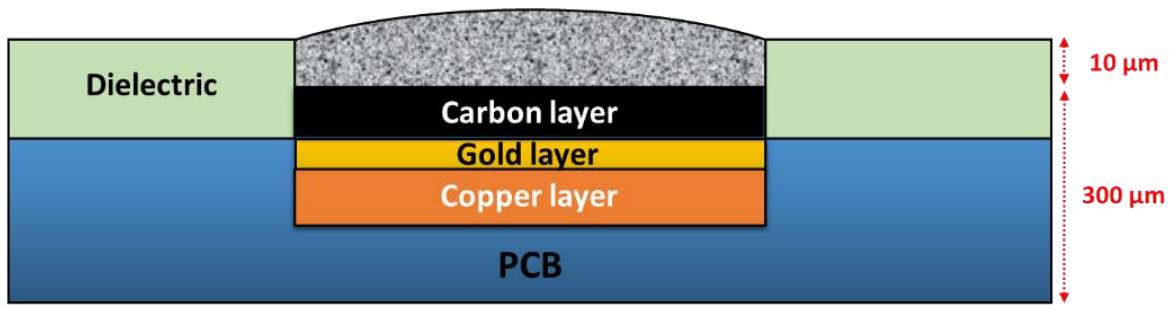

$\mathrm{NO} / \mathrm{NO}_{2}^{-}$- sensor

d

Lactate oxidase

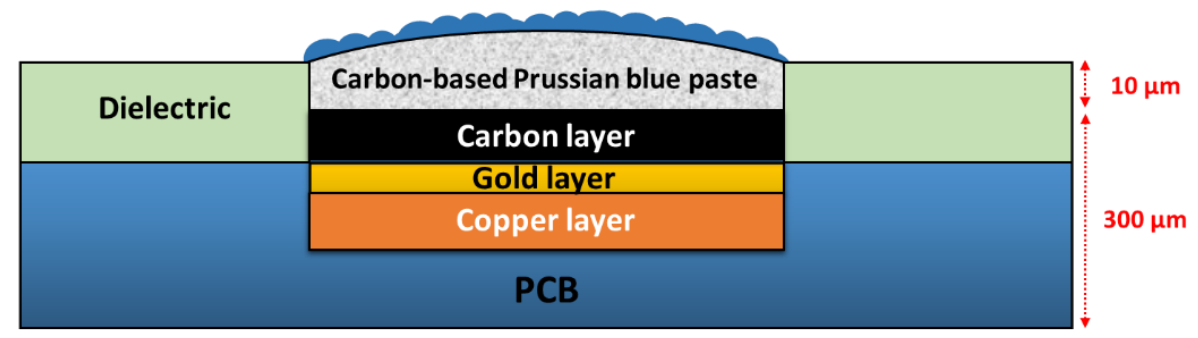

Lactate sensor

Fig. 2. Schematic representation in section view of different sensors layers of (a) $\mathrm{pH}$ sensor (b) $\mathrm{H}_{2} \mathrm{O}_{2}$ sensor (c) $\mathrm{NO} / \mathrm{NO}_{2}{ }^{-}$sensor and (d) Lactate sensor. 

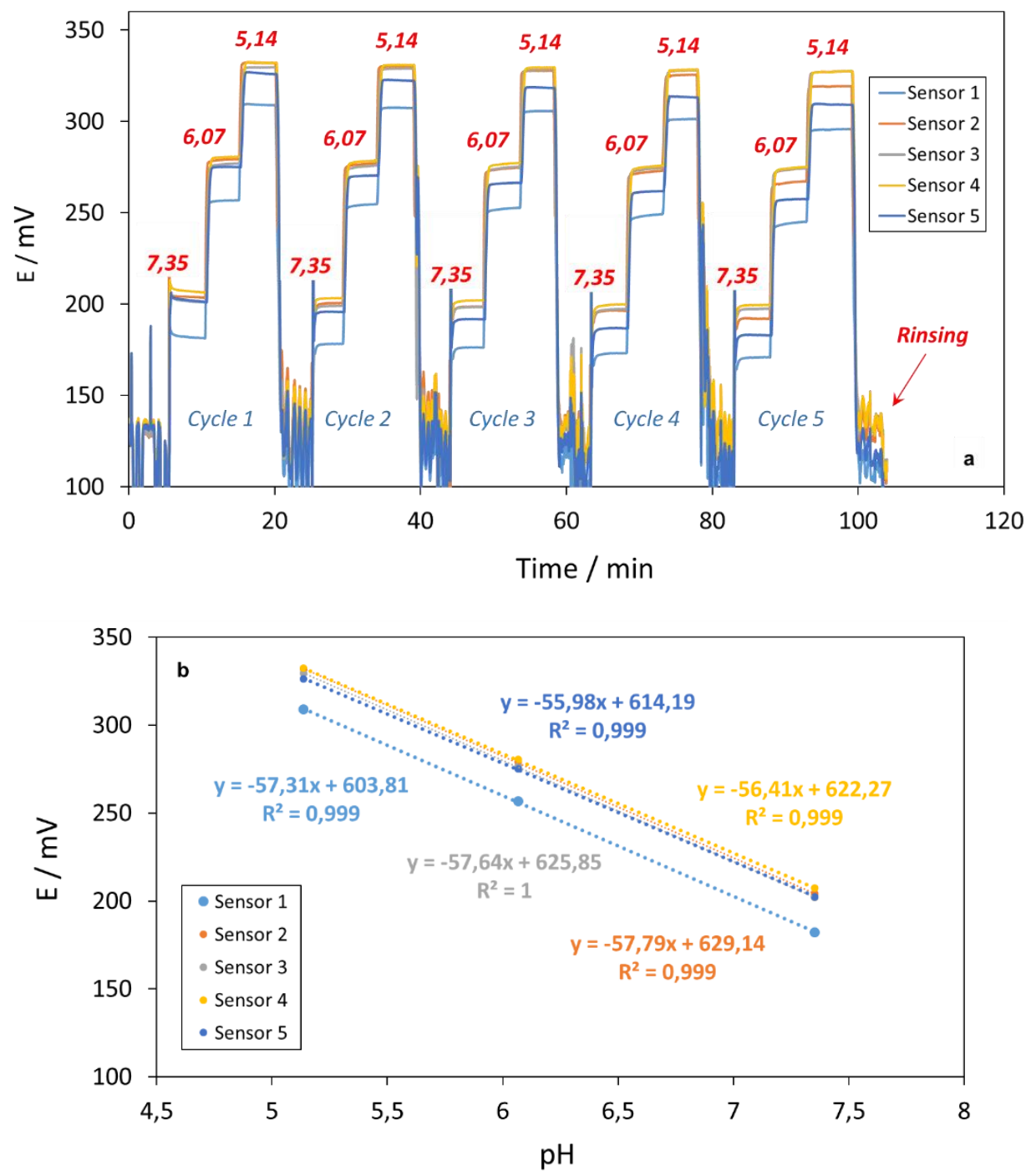

Fig. 3. (a) Electrochemical responses of pH sensors in PBS (1x) medium under flow rate conditions of $100 \mu \mathrm{L} \cdot \mathrm{min}^{-1}$. (b) Measured sensitivity of $\mathrm{pH}$ sensors. 

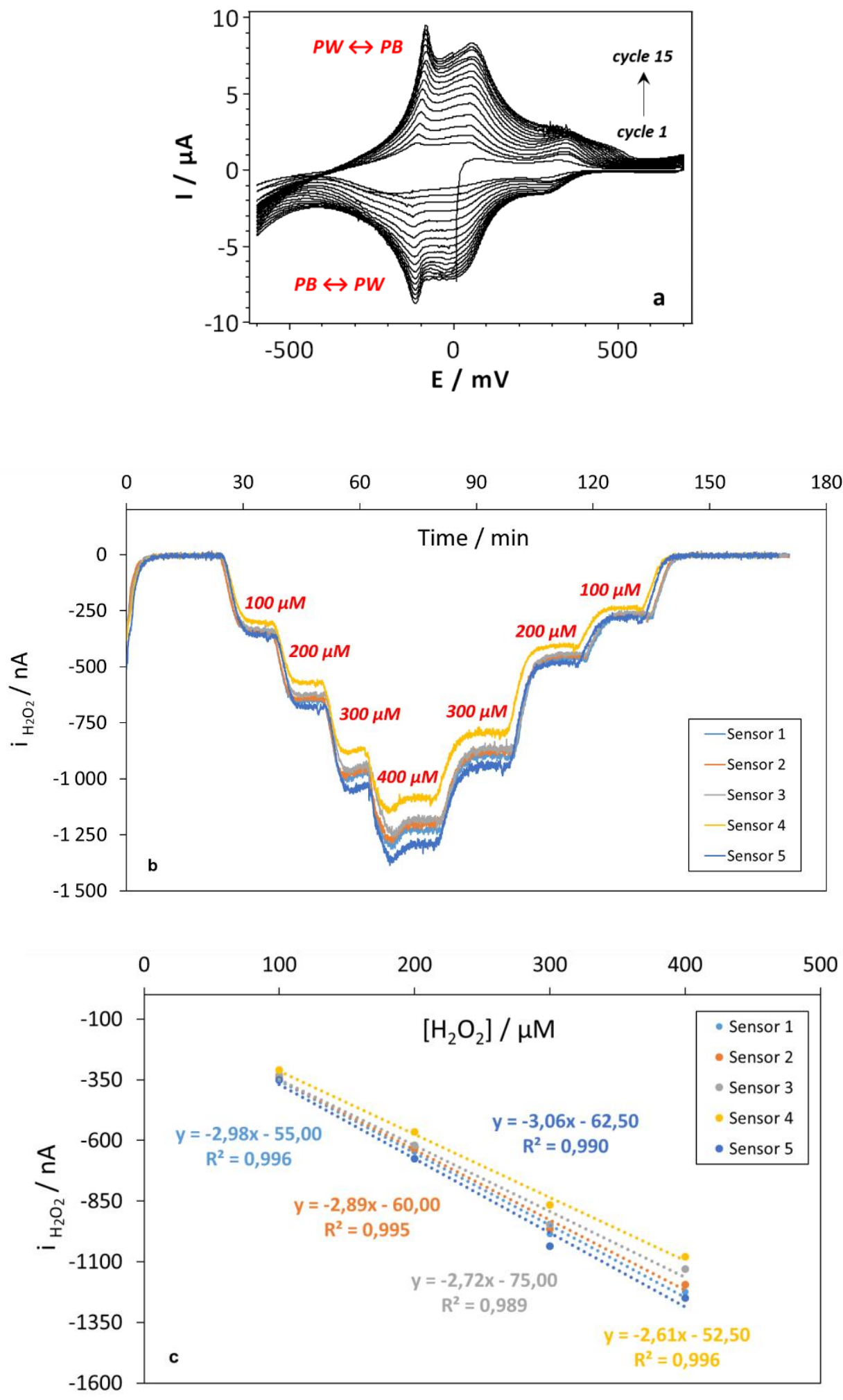

Fig. 4. (a) Cyclic voltammetric analysis in PBS (1x) medium at $50 \mathrm{mV} \cdot \mathrm{s}^{-1}$ of Prussian blue interface (15 cycling). (b) Amperometric responses at $-0.05 \mathrm{~V}$ vs Ag/AgCl of hydrogen peroxide sensors in PBS (1x) medium under flow rate conditions of $100 \mu \mathrm{L}$. $\mathrm{min}^{-1}$. (c) Calibration curves of hydrogen peroxide during electrochemical sensing. 

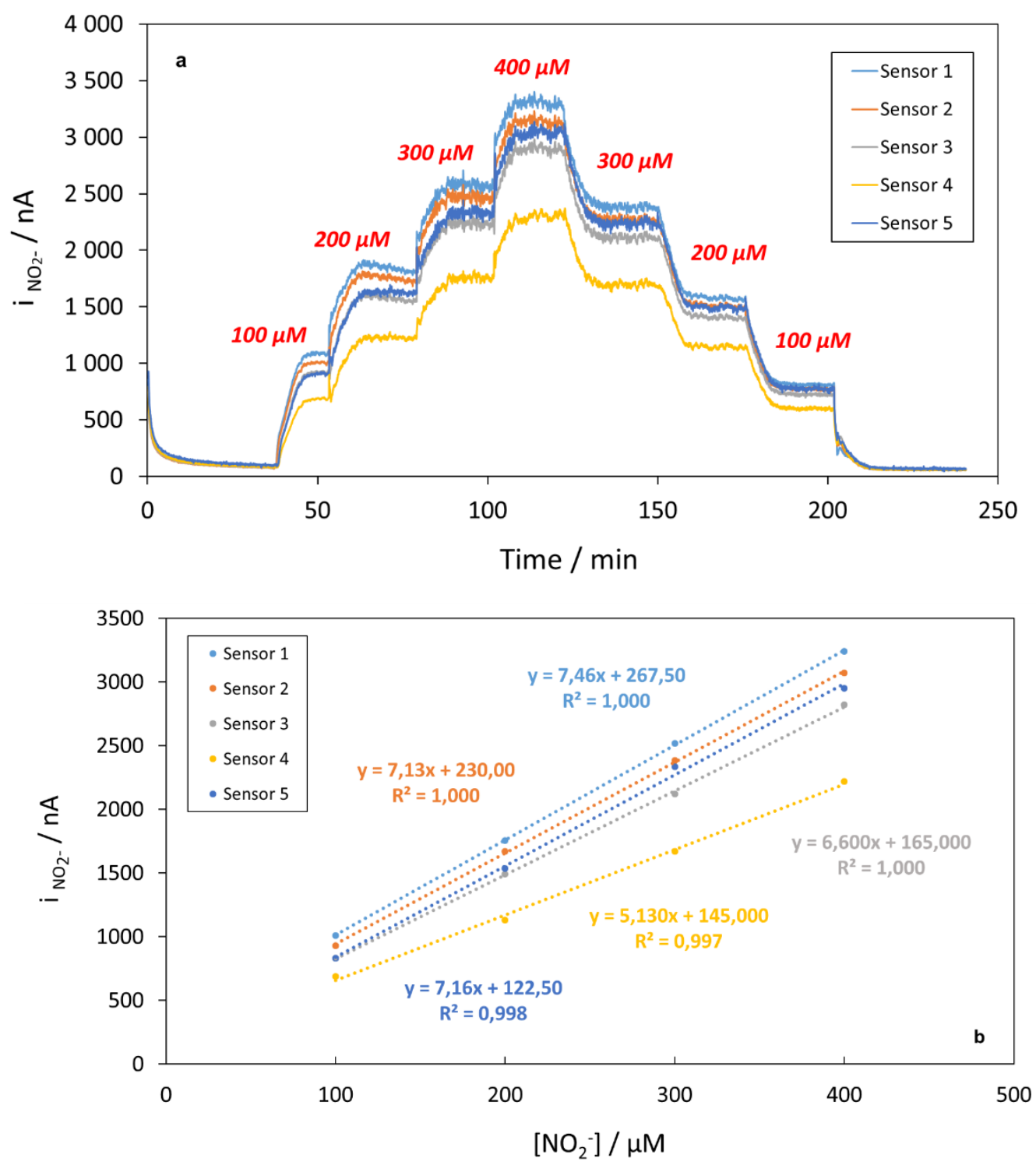

Fig. 5. (a) Amperometric responses at $+0.863 \mathrm{~V} v s \mathrm{Ag} / \mathrm{AgCl}$ of $\mathrm{NO} / \mathrm{NO}_{2}{ }^{-}$sensors in $\mathrm{PBS}(1 \mathrm{x})$ medium under flow rate conditions of $100 \mu \mathrm{L} \cdot \mathrm{min}^{-1}$. (b) Calibration curves of $\mathrm{NO}_{2}^{-}$during electrochemical sensing. 

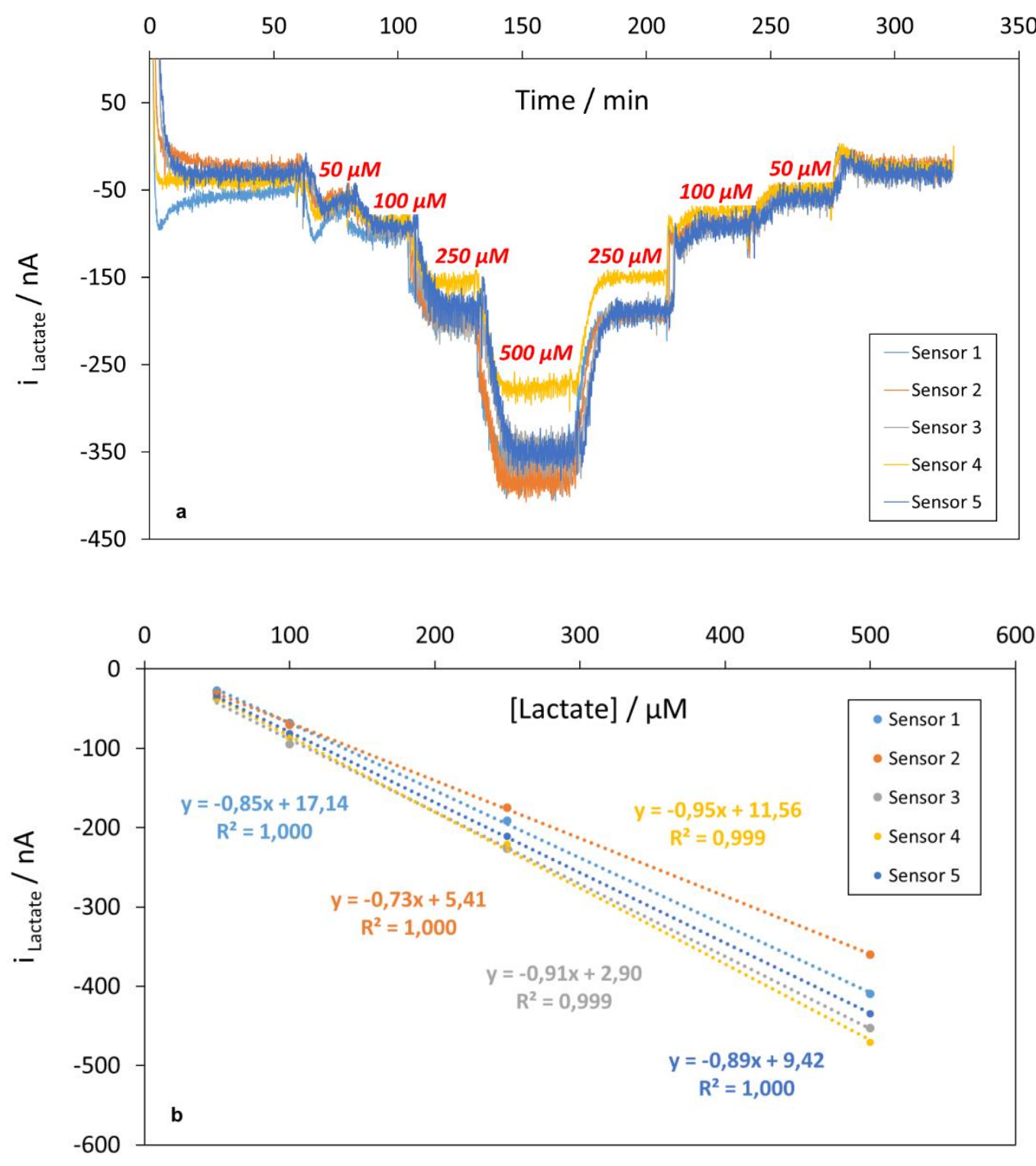

Fig. 6. (a) Amperometric responses at $-0.05 \mathrm{~V} v s \mathrm{Ag} / \mathrm{AgCl}$ of Lactate sensors in PBS (1x) medium under flow rate conditions of $100 \mu \mathrm{L} \cdot \mathrm{min}^{-1}$. (b) Calibration curves of Lactate during enzymatic electrochemical (bio)sensing. 

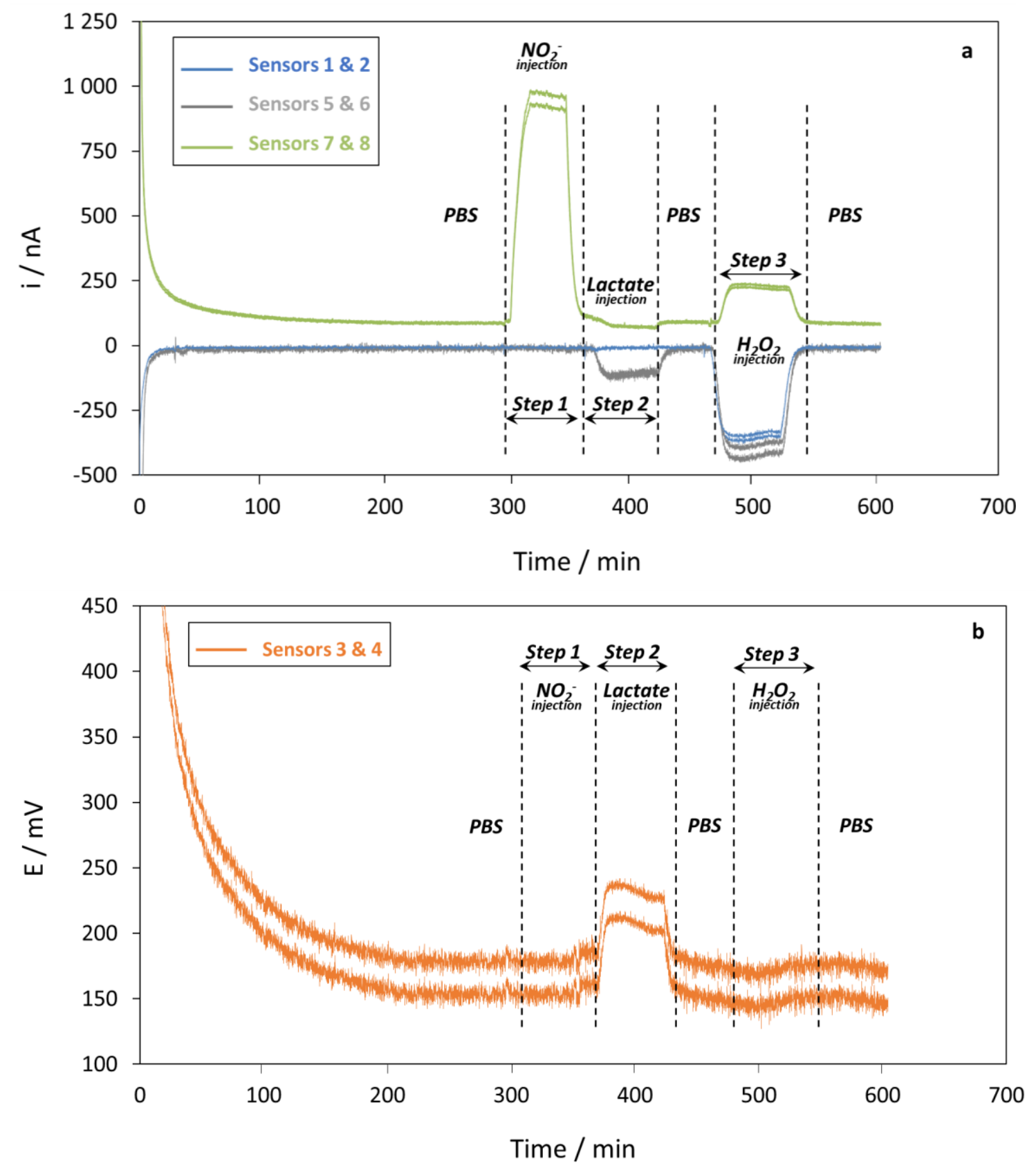

Fig. 7. (a) Amperometric responses of the sensors platform in a multiparametric configuration in PBS (1x) medium under flow rate conditions of $100 \mu \mathrm{L} \cdot \mathrm{min}^{-1}$ (sensors $1 \& 2$ / PB polarized at $-0.05 \mathrm{~V} \mathrm{vs} \mathrm{Ag/AgCl,}$ sensors $5 \& 6$ / lactate polarized at $-0.05 \mathrm{~V} v s \mathrm{Ag} / \mathrm{AgCl}$ and sensors $7 \& 8 / \mathrm{MB}$ polarized at $+0.863 \mathrm{~V}$ vs $\mathrm{Ag} / \mathrm{AgCl}$ ). (b) Potentiometric responses of $\mathrm{pH}$ electrodes (sensors $3 \& 4$ ) at equilibrium $v s \mathrm{Ag} / \mathrm{AgCl}$. 


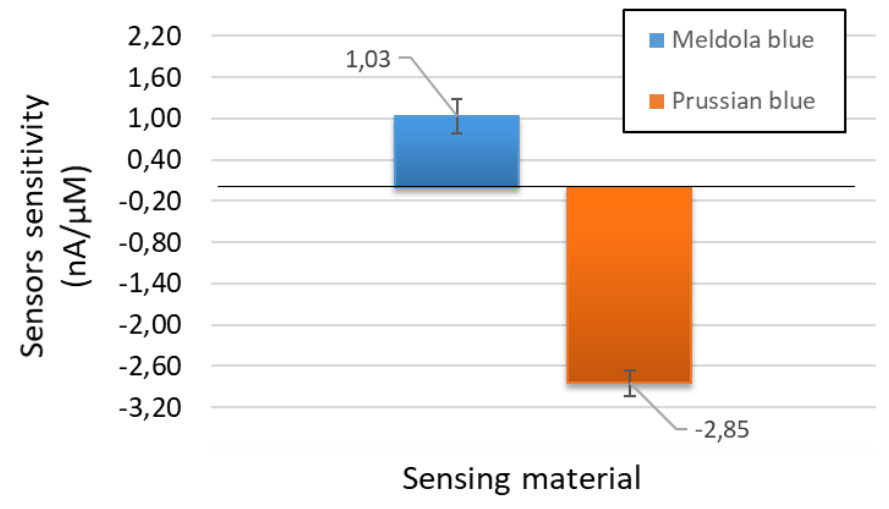

Fig. 8. Evaluation by amperometric analysis of hydrogen peroxide sensing sensitivity on different electrode materials of Meldola blue (at $+0.863 \mathrm{~V}$ ) and Prussian blue (at $-0.05 \mathrm{~V}$ ).

a

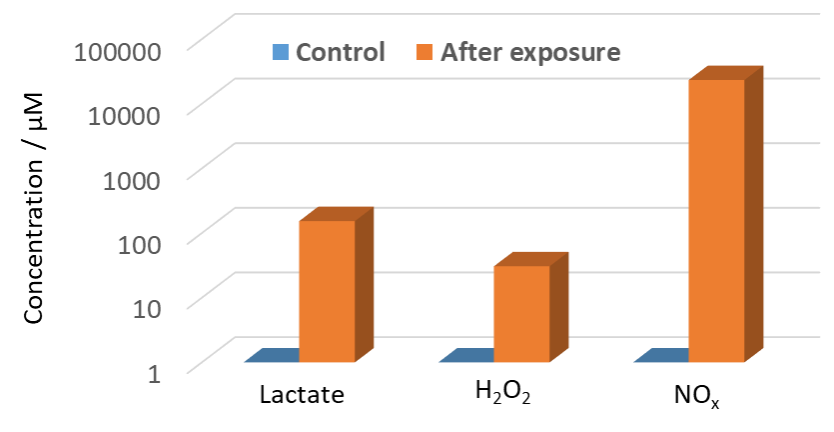

b

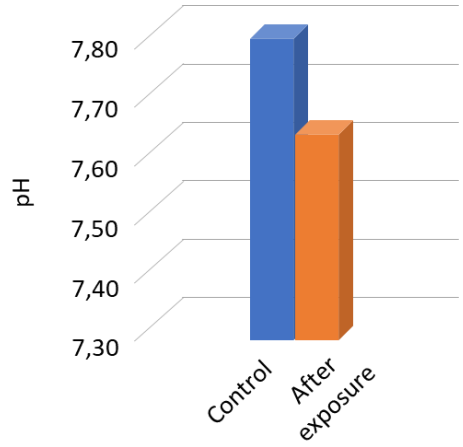

Fig. 9. (a) Effect of $24 \mathrm{~h}$ SDS exposure on lactate, peroxide and $\mathrm{NO}_{x}$ secretion from Caco2 cells and (b) changes of $\mathrm{pH}$ in cell culture media.

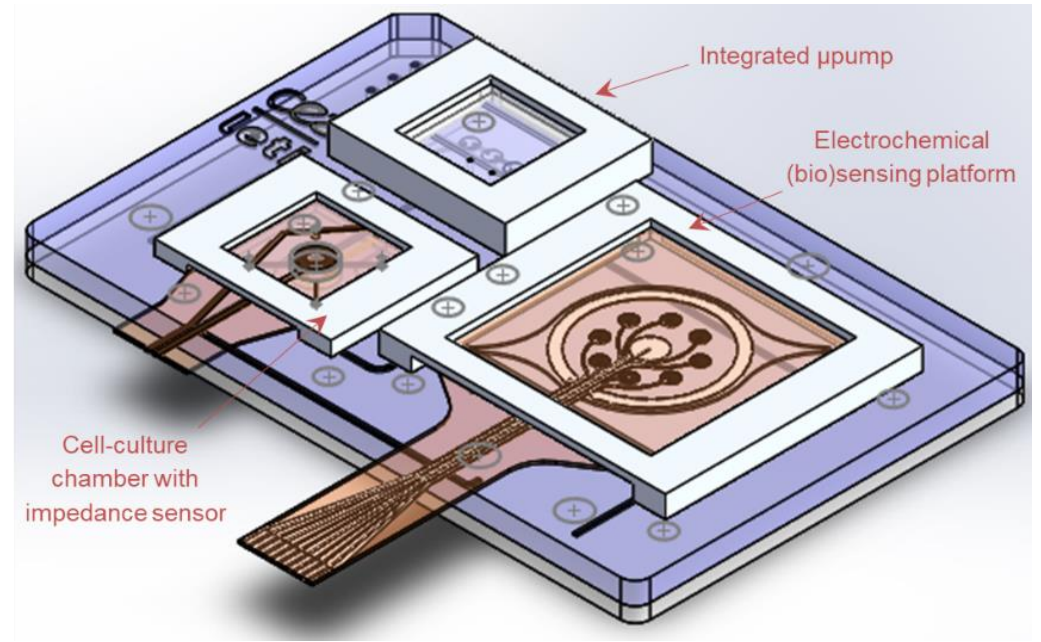

Fig. 10. 3D design of the bioreactor-embedded multiparametric (bio)sensing platform approach for cytotoxicity test. 